\title{
correspondence
}

\section{Unreal Science}

S:R,-As a qualified and practising scientist I wish to dissociate myself from your editorial of April 12. You allude to Geller and Velikovsky with terms like "nonsenses", "beliefs beyond science", and "pseudo-scientific ideas", and contrast these with "real science" and "science based on conventional ideas about the way a scientific investigation should proceed", and you declare that "scientists want to fight this distressing drift from the scientific way of thinking".

History is littered with ideas shown to be false by people bold enough to question their contemporary conventional science, often in the face of personal ridicule and even persecution.

Presumably you class Einstein's relativity theory with 'real' science, yet to back his theory Einstein makes a couple of postulates, not yet proven, whilst the unreal Velikovsky quotes source after source and fact after fact to back his. Where Velikovsky leaps eagerly into the jig-saw puzzle of the past and fits piece after piece together (rather unscientifically perhaps, but incorrectly ... ?) Einstein treads warily (and of course scientifically) through his mathematical maze, and deigns to emerge into the real world only at the end to explain Mercury's perihelion drift and to predict the deffection of light by the Sun. But wasn't there someone recently who found that the Sun was a little flatter than was previously thought which could account for half that drift (doesn't that make Einstein at least half wrong?), and isn't there someone else suggesting there's a planet, Vulcan, in there somewhere, or even maybe a whole asteroid belt? And just for one careless moment suppose that Velikovsky were right ... no, of course -much too unscientific!

I am not saying Einstein is wrong and Velikovsky right, but I believe both men's theories worthy of serious consideration. You say "Nature has a responsibility (that) guides us in the shoice of papers for publication". You have a right and a duty to edit, but that statement smacks of censorship. Velikovsky encountered censorship. More recently Dingle has met similar problems for daring to question Einstein.

I am not young nor am I by any neans a pseudo-scientist, nor are a number of colleagues who share my opinion. I want no part in any science which operates with a closed mind, and I will encourage the young, and old, to drift from such a way of thinking, though I hardly need to. Your own editorial will do that well enough by itself.

\section{Southminster, Essex, UK}

\section{P. WARLOW}

\section{Cancer research}

Sir,- Your correspondent Brian Ford comments (Nature, May 24) on the abundance of data and paucity of concepts in cancer research. A cursory survey of the literature strongly supports this point.

For example, 10 randomly chosen issues of Excerpta Medica-Cancer were found to cite about four thousand papers, of which a total of nine were classified as Theories of Carcinogenesis. It is as though $99.8 \%$ of the +ime taken to solve a jig-saw puzzle went on gathering heaps of pieces and $0.2 \%$ went on fitting the pieces together. This imbalance conflicts with the widespread belief that cancer research needs "more facts and fewer theories". The opposite appears to be the case.

$$
\text { Yours faithfully, }
$$

T. E. WHELDON

Department of Clinical Physics and Bioengineering,

Glasgow, UK

\section{Geology $\supset$ geophysics?}

SiR,-The President of the Geological Society of London, the Director of the Institute of Geological Sciences and Professor $P$. Allen have informed $u^{1}$ "that geophysics is a necessary and important part of geology" and in case the reader misses the point they say it again ". . . of earth science, that is of geology." That a present and past-and one hopes future-president of the oldest Geological Society in the world should so write is doubtless a Freudian slip, as earlier this century the society refused to take geophysics under its wing, this important task being faithfully discharged since then by the Royal Astronomical Society to the mystery of our friends abroad. In the Cambridge Tripos Part II twenty years ago the question was set: "Geophysics dots the i's and crosses the t's of geology. Comment." I seem to recall that Professor Allen was an examiner. Perhaps those who simply answered
"But, of course" qualified for firsts!

I have always worked, as have your correspondents, for more understanding and dialogue between geophysicists and geologists, but also between geophysicists and astronomers and physicists: problems of the Earth's rotation, Earth and planetary magnetic and gravitational fields, solid state physics of interiors, lunar and planetary formation are of more interest to the latter groups than to geologists. Geologists on both sides of the Atlantic who suppose-perhaps understandably as the highways of earth science are presently congested by careering bandwagons-that continental drift, seafloor spreading, plate tectonics and plumes is the whole of geophysics might do well to read again Sir Harold Jeffreys's The Earth or study Professor A. H. Cook's Physics of the Earth and planets.

As Sir Peter Kent is also Chairman of the Natural Environment Research Council (NERC), it seems desirable to emphasise that geophysics is a discipline in its own right separate from -and one might add older thangeology. The NERC awards of research studentships for the Earth Sciences seem to me to be seriously overweighted $^{2}$ at present in favour of geo$\operatorname{logy}$ as against geophysics by about $7: 1$. This disparity does not reflect the relative need for highly trained people in these two disciplines nor the present intellectual challenges in the two subjects: it reflects the fact that there are some 45 departments of geology in British Universities.

Thus, as Chairman of the Royal Society committee which launched the European Geophysical Society, I welcome the 1975 "Europe from crust to core" meeting as a further step in European scientific cooperation. I hope that the formation of a 'Pan-European Society of Earth Scientists' (as distinct from a European geological society) is not seriously mooted if only on logistic grounds. Geophysicists interested in geological problems will surely come, as I hope to myself, to Reading and geologists concerned especially with tectonics will continue to join us at the European Geophysical Society's annual meetings.

\section{Yours faithfully,}

S. K. RUNCORN

University of Newcastle upon Tyne

I Nature, June 14, 249, 608 (1974).

2 N.E.R.C. Research Studentships 1974. 